\title{
O IMPACTO NO ENSINO- APRENDIZAGEM NA PREVENÇÃO A VIOLÊNCIA A CRIANÇA
}

\author{
Daniele Vignoli Ribeiro ${ }^{1}$ \\ Josiane Bravo Almeida ${ }^{2}$ \\ Cristiane da Silva Gabriel Capeletto ${ }^{3}$ \\ Andreia Freitas de Souza Werneck ${ }^{4}$
}

RESUMO: Visto que vivemos em um mundo onde muitas das vezes é preciso repetir os valores humanos, este artigo, abordará o tema "Cuidado humano", com o intuito de levar as pessoas a refletir sobre a condição humana. Assim, o objetivo deste é descrever o impacto do ensino aprendizagem de enfermagem na prevenção a violência a criança. A metodologia utilizada são as oficinas de criatividade e sensibilidade oferecidas por Cabral (1999), que se mostraram adequadas para o enfrentamento de questões complexas como a prevenção da violência contra crianças/adolescentes e o manejo de famílias com doenças infantis. As oficinas têm como intuito criar um espaço de reflexão sobre o cuidado humanizado a partir das vivências dos alunos. O resultado deste relato de experiência educacional visa desenvolver conteúdos sobre o cuidado humanizado à criança/adolescente e sua família com os alunos do curso final de enfermagem. Isso confirma a importância da introdução de métodos alternativos no processo de ensino-aprendizagem da universidade, a fim de construir conhecimentos e focar na experiência.

Palavras- chave: Cuidado Humano. Ensino. Oficinas de Criatividade

\section{INTRODUÇÃO}

Abordar o tema "cuidado humano" nos leva a refletir sobre a condição humana, visto que vivemos em um mundo onde muitas vezes é necessário repetir os valores humanos. Para a área da saúde, essa é uma questão fundamental, visto que, diante dos fenômenos existenciais como saúde e doença, as ações de cuidar do ser se desdobram nas etapas

\footnotetext{
${ }^{1}$ Enfermeira. Lattes: http://lattes.cnpq.br/3928492747219438. E-mail: vignoliribeiro@gmail.com

${ }^{2}$ enfermeira.e-mail: josibravo@hotmail.com.

3 Enfermeira.e-mail: cristianedasilvagabriel@gmail.com.

${ }_{4}^{4}$ Gerente de enfermagem. E-mail: andreia.fersouzas6@gmail.com.
} 
evolutivas, em momentos existenciais críticos, como o nascimento, a doença e a morte (CABRAL, 1999).

Doença e morte são fatos da existência humana. São momentos que revelam a fragilidade de estar no mundo, que gera dor, sofrimento e situação traumática. Os acontecimentos com o corpo influenciam a existência do ser no mundo, pois o corpo constitui sua presença no mundo antes do outro, ou seja, o ser encarnado coexiste com o outro (VASCONI, 1994). Corpo é: "a forma específica da presença do homem no mundo" (SANTIN, 1995).

Para o ser-no-mundo, a doença é um fato existencial complexo e difícil, pois desorganiza seu mundo, muda seu corpo e imagem simbólica, agrava sentimentos e reações, a criatura precisa reconstruir sua forma de ser no mundo: um ser corpóreo e simbólico, com limites.

O Diploma de Enfermagem visa, com base nas Diretrizes Instrucionais Nacionais, implementar um currículo que favoreça a formação do enfermeiro generalista, humanístico, crítico e reflexivo, baseado em princípios científicos e éticos.

$\mathrm{Na}$ atividade de ensino buscam-se estratégias que auxiliem o aluno a aprender a refletir e a questionar sua prática. Este relato é uma reflexão sobre a construção de cenários de aprendizagem que ofereçam subsídios para que os acadêmicos aprendam a enfrentar as realidades existenciais da saúde e da doença no mundo do cuidado. Considerando que diversos fatores podem impactar no ensino aprendizagem, busca nesta pesquisa responder o respectivo questionamento: Quais estratégias podem ser aplicadas ao ensino aprendizagem acadêmica, para fortalecer a abordagem na prevenção a violência a criança?

\section{DESENVOLVIMENTO}

A enfermagem, como atividade humana, existe há muitos anos, embora seja considerada uma profissão jovem. Expressando-se como atividade profissional, tem se firmado e desenvolvido a partir da construção e consolidação de seus conhecimentos, pois utiliza a pesquisa como instrumento de conhecimento teórico-prático, como desafio de transformação (VASCONI, I994; SANTIN, 1995). 
A certa altura da história, a enfermagem torna-se parte invisível de uma atividade científica na qual representa apenas as engrenagens de uma máquina, reproduzindo um modelo de saúde desgastado. Sua ação, neste espaço-tempo, não é visível - ela é técnica e científica.

$\mathrm{Na}$ ciência tradicional, a enfermagem não teve potencial para crescer/renovar-se, para além do que já foi realizado/antecipado, ao qual incorporou, isto é, conhecimentos técnicos, tecnológicos, éticos e jurídicos.

Para ir mais longe, precisava incorporar uma nova atitude, encontrando no homem o estímulo para seu reencontro. Assim, em um processo coletivo de avaliação de suas ações, o enfermeiro percebe sua essência - o cuidado humano.

E passam a expressar em seu cotidiano esse cuidado ético e estético, real e visível. Desde então, textos foram produzidos, pesquisas nessa linha e o cuidado se desenvolveu como expressão da arte do saber de enfermagem.

O cuidado de enfermagem é um edifício articulado ao cuidado real que surge, inserindo conceitos esquecidos voltados para o zelo, o cuidado, à medida que a profissão repensar e reformular seus conceitos, numa caminhada evolutiva de construção e/ou revisão do seu fazer.

Considerando as marcantes transformações no mundo, na saúde e nas ciências, e percebendo a necessidade de reagir, de superar as barreiras do tecnicismo, preencher lacunas do conhecimento e aproximar a ciência do homem, a enfermagem rompe com paradigmas institucionalizados, buscando seu acesso à arte, voltando-se para o homem.

Seguindo essa mentalidade, em um movimento dinâmico, seu desafio passou a ser quebrar protocolos, desnudar suas rotinas de grande valor técnico e fortalecer novas perspectivas.

A enfermagem, portanto, passa por mudanças profundas, buscando outra forma de cuidar. Para tanto, visa afastar-se da ajuda e enxergar um novo horizonte repleto de possibilidades, como o cuidado que preserva o indivíduo em sua singularidade, integridade e contexto de vida, privilegiando o ponto de vista holístico. 
Para dar forma a esse modo de ação, ela capta aspectos peculiares ao homem e à enfermagem, como o cuidado, a sensibilidade, o contato, a relação terapêutica, recriando seus contornos com o traço marcante do artista que se recupera.

Segundo Waldow (1998), o cuidado originou-se do interesse, do cuidado e do amor e se relaciona à enfermagem por meio da associação da mulher com o materno e educacional, com foco no crescimento do indivíduo.

A partir das práticas de cuidado materno, emergência e ameaça do adoecimento, a mulher investiu-se no papel de cuidadora e desenvolveu as ações de bem-estar e cura. Com o tempo, dedicou-se a atividades de conforto e minimização do sofrimento (WALDOW, 1998).

Assim, a enfermagem tem se movido para o cuidado efetivo, implementando o cuidado em seu cotidiano como forma de se relacionar, com compromisso, responsabilidade e zelo. Cuidar envolve olhar para o outro, criar condições para o outro crescer, estar disponível para vê-lo e ouvi-lo, a fim de confortar, tranquilizar, proteger (WALDOW, 1998).

Cuidado significa cuidado e ocupação, faz parte da estrutura das pessoas enquanto vivem (SANTIN, 1995). A necessidade de cuidado aumenta em momentos críticos da vida: nascimento, doença e morte.

A enfermagem é uma ciência humana, uma arte que lida com as experiências humanas no processo saúde-doença e se transmite por meio de transações pessoais, científicas, estéticas e éticas no cuidado humano (WALDOW, 1998).

O processo de enfermagem é: o desenvolvimento de ações, atitudes e comportamentos baseados no conhecimento científico, experiência, intuição e pensamento crítico, realizados no ou com o paciente/cliente a fim de promover, manter e/ou restaurar sua dignidade e integridade humana (incluindo o senso de plenitude física, social, emocional, espiritual e intelectual e realização nas fases de vida e morte) (NUNES, 1996). 
A enfermagem é uma ciência, além de uma arte humanística que promove e mantém a saúde por meio de intervenções de enfermagem e ajuda as pessoas a superar os efeitos da doença como fenômeno social, existencial e cultural.

Saúde é um estado de bem-estar culturalmente definido, avaliado e praticado que reflete a capacidade dos indivíduos e/ou grupos de realizar suas atividades diárias de forma satisfatória (WALDOW, 1998). Dentre os principais componentes da enfermagem, o conhecimento é fundamental para o processo de enfermagem, ou seja, quem é o ser cuidado, suas faculdades, limitações e necessidades, sendo importante também conhecer as faculdades e limitações do cuidador (MAYROFF, 1971).

A paciência é também mais um elemento do processo de enfermagem, ou seja, o crescimento do outro em seu próprio tempo e forma, tolerância às limitações, confusão e incursões à existência. A veracidade, por sua vez, é um requisito necessário para que o cuidador não minta deliberadamente e engane os outros.

Outro crescimento no outro, reconhecendo sua independência e libertando-os, inclusive a humildade, um dos elementos que exige que o cuidador esteja disponível para aprender sobre o outro e sobre si mesmo, superar o pretexto mostrar falsa modéstia e avaliar seus próprios limites e poderes.

A esperança é outro aspecto essencial da preocupação em acreditar no potencial do outro. Por fim, a coragem é descrita como o componente final do cuidado, pois o cuidador deve mergulhar no desconhecido e contar com a sua própria capacidade e a do outro para crescer.

O cuidado é compreendido pelo cuidador a partir do encontro com o outro. É um processo complexo com diversos significados que envolve o paciente, a família e os membros da equipe de saúde (MOTTA, 1997). Se esforçando para ser cuidado, tentando ser do seu jeito e entendendo seu mundo e cuidando de si mesmo.

O cuidado de crianças e jovens é feito pela família, sua referência no mundo. A família é o espaço que oferece à criança amor, carinho, proteção e segurança e cria as condições para que ela cresça e se desenvolva como ser no mundo. 
A doença cria uma ruptura na dinâmica familiar, a criança e a família entram em outro mundo, um mundo estranho, o mundo hospitalar. A família começa a experimentar outra dimensão do existente. Seus planos para o futuro estão ameaçados, ele começa a enfrentar a possibilidade de perder seu filho e uma série de sentimentos surgem: medo, culpa, raiva (MOTTA, 1997).

A vida diária está turbulenta e exige a mudança de casa e de outras crianças, e a dinâmica familiar precisa ser redimensionada.

A equipe de saúde, sensível à dor e ao sofrimento físico e emocional da criança, se solidariza com a família, estabelece vínculos e cria uma rede de informação e apoio. A presença da família é vital para o cuidado da criança, significa segurança, preserva o mundo da criança, mantém os laços afetivos, representa o vínculo da criança com o hospital mundial.

Ao estabelecer uma relação de ajuda com a criança/adolescente e sua família, o cuidador passa a exercer um papel de apoio, adaptando a criança e a família a essa facticidade existencial.

A família ganha coragem e força para continuar a caminhada com a criança doente, afirma-se como fonte de afeto, cria segurança e apoio para a criança e fortalece a esperança como auxílio terapêutico.

O enfrentamento das causas e efeitos da violência doméstica no mundo infantojuvenil é outro tema relevante no atendimento às crianças e adolescentes e seus familiares. A preocupação com a integridade física e psicológica da criança tem estado no centro das atenções no Brasil e foi traduzida da legislação brasileira em I99o pela Lei 8. 069 - Estatuto da Criança e do Adolescente (CEA) (MINISTÉRIO DA SAÚDE, I99I).

Atualmente, há um aumento alarmante da violência e acredita-se que isso deva estar atrelado ao aprofundamento do conhecimento na área e a uma divulgação mais efetiva da violência doméstica contra crianças e adolescentes na mídia. 
O abuso e a negligência com crianças/adolescentes são encontrados principalmente no ambiente familiar. A violência se manifesta de diferentes formas: física, psicológica, sexual e negligenciada.

Diversos ambientes de moradia têm buscado uma série de medidas para promover estratégias de proteção de crianças e adolescentes, por se tratar de uma faixa etária sujeita a problemas físicos e emocionais.

Há um número crescente de crianças vítimas de abandono e/ou abuso em hospitais. Esse fato tem mobilizado profissionais de diversas áreas do conhecimento, inclusive da área da saúde, para o desenvolvimento de estratégias de prevenção da negligência e da violência contra crianças e adolescentes, bem como o compromisso de formar profissionais preparados para enfrentar esses níveis de realidade.

A família é uma unidade dinâmica inserida em um contexto social, uma complexa organização de relações íntimas e construtivas de identidade pessoal que dá forma e sentido às interações entre os elementos do núcleo familiar (BIASOLI, I999).

A violência vai além da força física e da coerção pessoal e é sutilmente descrita como coerção psicológica, desigualdade social (GRANDO, 1999).

O fenômeno da violência surge como uma realidade no mundo das relações familiares. A família é um lugar de refúgio, de afeto, mas pode ser caracterizada como um ambiente de cuidado ou descaso com crianças e adolescentes.

O enfermeiro é um profissional preparado para o cuidado humano com o objetivo de promover qualidade de vida e manter a integridade do ser. Sensibilidade, respeito ao próximo, bioética em relação ao conhecimento técnico-científico são elementos fundamentais para a atuação de um profissional crítico, reflexivo e comprometido com a qualidade do cuidado.

Durante o processo de enfermagem, a presença do enfermeiro é fundamental, pois a presença do enfermeiro no mundo hospitalar significa: 


\begin{abstract}
Estabelecer laços pessoais de intersubjetividade, onde há espaço para a confiança e a esperança... Que esta presença tivesse mãos hábeis e carinhosas. Hábeis porque fundariam conhecimentos seguros e dotados de técnicas eficazes; carinhosas, porque inspiradas num coração sensível. Acima de tudo que está presença tivesse um rosto. Um rosto, comunicativo, expressivo, falante, mesmo no mais profundo silêncio; e o rosto fosse iluminado por um olhar humano, como um elo que me une a todos os olhares amigos que esperam a restauração da plenitude da vida; ou, então o último gesto que comunica com a paisagem da vida que desaparece...que esse olhar ...mais que um adeus de despedida, fosse uma agradável lembrança e eterna de um mundo que fica (SANTIN, 1998).
\end{abstract}

\title{
OFICINAS DE CRIATIVIDADE
}

Os workshops são realizados usando o método criativo sensível. Essa técnica proporciona um espaço de reflexão e construção de conhecimento para os acadêmicos de enfermagem que "permite a preservação da singularidade de cada participante do grupo que está adquirindo sua experiência" (CABRAL, 1999).

O objetivo da utilização deste recurso é a oportunidade de combinar ciência e arte, criatividade e sensibilidade, utilizar diferentes dispositivos para conduzir as oficinas e estabelecer uma relação dialógico-dialética entre acadêmicos e professores.

Pretende-se, portanto, sensibilizar e educar os alunos para a realidade existencial de crianças e adolescentes em situação de sofrimento físico e emocional devido ao abandono e/ou violência e para as vivências familiares com o adoecimento grave da criança.

A dinâmica da criatividade fomenta o diálogo entre os participantes, problemas ou problemas fundamentais, conceitos e experiências são examinados e subsidiados através da produção artística.

As oficinas serão realizadas com turmas de seis acadêmicos e a dinâmica é dividida em três momentos. No primeiro momento são dadas as instruções do método e iniciadas atividades criativas baseadas nos temas das "vivências infantis" na primeira oficina e na segunda "cenas familiares".

No segundo momento, são apresentadas as produções artísticas (pintura, desenho, modelagem, depoimentos escritos etc.) que foram realizadas individualmente ou em grupo com o objetivo de criar espaços de discussão e reflexão, aprofundar o tema em questão, trocar ideias e conceitos e experiências. $\mathrm{Na}$ discussão são avaliados os vínculos com o referencial 
teórico, as opiniões, os estudos realizados nesta área e avaliados os aspectos relevantes para o tratamento.

No terceiro momento, são apresentados referenciais teóricos que resgatam aspectos importantes do tema, dão continuidade à reflexão e construção coletiva do conhecimento. Finalmente, é realizada uma avaliação dinâmica.

A utilização do Método Criativo Sensível é eficaz no desenvolvimento de conteúdos complexos como a prevenção do abandono e da violência contra crianças e adolescentes e o atendimento a famílias de crianças hospitalizadas com doenças de prognóstico reservado, considerando sua informalidade e ricas formas de expressão. Este método permite ao acadêmico compartilhar experiências com o grupo que considera mais importante, às vezes relacionadas de forma muito criativa.

A realização das oficinas favorece a construção coletiva do conhecimento, com a participação ativa de acadêmicos e professores. Procuramos analisar, com o auxílio do suporte teórico, a situação sob diversos ângulos, refletindo sobre essas questões, despertando o interesse do acadêmico no cuidado à criança/adolescente e família que vivem a dolorosa realidade da violência e/ou adoecimento.

Outro ponto relevante é perceber a sensibilidade e o despertar do interesse dos acadêmicos, a partir de suas histórias, pela realidade das crianças/adolescentes e famílias em situação de dor física e emocional.

Destaca a importância atribuída ao papel do cidadão e dos profissionais de saúde na proteção dessas crianças/adolescentes e famílias em situação de risco.

No processo de cuidar, quando o cuidador estabelece uma relação de ajuda com o cuidador e sua família, pautada no respeito, na liberdade, no compromisso e na compreensão do significado da experiência de adoecimento para o grupo familiar, com compaixão, o cuidador exerce o papel de facilitador. na adaptação e enfrentamento da doença da criança.

A equipe de saúde pode auxiliar neste processo, desde que esteja tecnicamente equipada, garantindo tratamento competente, mantendo uma relação ética e estética, onde a intersubjetividade e a sensibilidade estão presentes. A ação de cuidado deve estar 
impregnada de solicitude, respeito, carinho e cooperação, estabelecendo uma rede de apoio à criança/adolescente e a família.

O profissional de enfermagem, desde sua formação acadêmica, deve estar preparado para enfrentar a complexa realidade do mundo do cuidado, tendo como valores existenciais a sensibilidade e a solicitude na construção de uma prática centrada no Ser, a partir do Ser.

\section{CONSIDERAÇÕES FINAIS}

Concluindo, podemos destacar que a valorização da abordagem qualitativa pelos pesquisadores da enfermagem reafirma que esses profissionais têm buscado caminhos epistemológicos para ampliar as possibilidades de olhar o cliente como um todo holístico, evitando a fragmentação do ser humano. Entendemos que houve um afastamento proporcional do modelo cartesiano em busca de uma melhor adaptação dos métodos de pesquisa aos objetos de estudo da enfermagem.

Pensar o cuidado de enfermagem é pensar a dinâmica do cotidiano que envolve o ser que cuida e o ser que cuida, ambos em um mundo de trocas, onde se aprende, sofre, espera, acredita, sonha, a partir de concepções socialmente construídas sobre as relações entre profissionais, clientes e equipes. Nessa reflexão, compreendemos o quanto é relevante apoiar o cuidador de quem cuida e no que é cuidado.

No entanto, a visão holística e individualizada do cliente será de pouca utilidade para melhor atender às suas necessidades se o mantenedor humano desse cuidado permanecer fora dessa visão.

A pesquisa enfoca o cuidado e o cuidador destaca as preocupações dos enfermeiros sobre a lacuna do cuidado. $\mathrm{O}$ modelo teórico sustenta a práxis, porém, se não houver associação entre o modelo teórico e a práxis, podem surgir conflitos que criam barreiras à relação e ao cuidado humanos. Para que a cura ocorra, é fundamental que haja outro ser que desenvolva as situações de cuidado.

O cuidador é aquele que promove o cuidado; que estabelece as condições para o outro crescer, valorizando-o enquanto espera que se desenvolva por si, favorecendo oportunidades de demonstração das próprias capacidades, o que pressupõe interação, 
compromisso, envolvimento, afeto, zelo, carinho, empatia, sinceridade e dedicação como componentes fundamentos do cuidado.

É um aspecto intrínseco da prática de enfermagem, que no cotidiano da assistência deve buscar respeitar a integridade, as características do cliente e sua história de vida. $\mathrm{O}$ enfermeiro, portanto, deve ter mais do que capacidade técnica e competência profissional na realização dos procedimentos, mas também compreender a importância de estar presente, de se dedicar e de se envolver no cuidado deles.

Embora não tenha sido possível captar muitos resumos referentes aos teóricos de enfermagem, acreditamos que os enfermeiros, ao pesquisar teorias, se apropriaram desse conhecimento para desenvolver o cuidado humano, a partir de referências que centralizam a essência da enfermagem.

Vale lembrar que a promoção do conhecimento e do conhecimento permite que o profissional se aprimore. É imprescindível permitir mais pesquisas sobre os problemas do cuidado e/ou do cuidador, para promover o desenvolvimento da profissão, sem a qual a evolução do cuidado consciencioso e humano não seria possível.

Nossos resultados também podem levar a uma reflexão crítica sobre a importância da qualidade dos resumos publicados no banco de teses da CAPES, visto que estes fornecem subsídios para o desenvolvimento de outros estudos. Nesse sentido, é de grande valia que os pesquisadores mencionem o referencial utilizado, bem como outros indicadores de igual importância.

O conhecimento produzido deve ser veiculado para que o profissional pense e perceba as coisas com um olhar diferente. Uma das formas de transmissão do conhecimento é por meio da divulgação científica, pois quando não divulgado impossibilita a aplicação, crítica e geração de novos conhecimentos (VASCONI, 1994)

O conhecimento científico da enfermagem fornece subsídios para a prática da enfermagem, bem como promove a reflexão sobre a prática, o que permite ampliar os recursos para a construção de novos conhecimentos. Com essas informações, destacamos que embora o número de produções atualmente seja expressivo, ele ainda precisa ser ampliado para o contínuo avanço da profissão de enfermagem. 


\section{REFERÊNCIAS}

BIASOLI, A. Z. M. M. Aproximações Teóricas e Conceituais de Família e Violência no Final do Século XX. Texto Contexto Enfermagem, Florianópolis (SC) maio/ago;8(2):65-75 1999.

CABRAL, I. E. Aliança de saberes no cuidado e estimulação da criança bebê. Rio de Janeiro: Escola de Enfermagem Anna Nery;1999.

GRANDO, C. Violência Física. In: Violência Doméstica Contra Criança e Adolescente. Centro Crescer sem Violência/Secretaria de Estado do Desenvolvimento Social e da Família do Estado de Santa Catarina. Florianópolis (SC): IOESC;1999.

MAYROFf, M. A Arte de Servir ao Próximo para Servir a Si Mesmo. Rio de Janeiro: Record; i97I.

BRASIL, Ministério da Saúde. Estatuto da Criança e do Adolescente. Brasília (DF): MS;I99I.

MOTTA, MGC. O ser doente no tríplice mundo da criança, família e hospital: uma descrição fenomenológica das mudanças existenciais [tese de Doutorado em Enfermagem]. Florianópolis (SC): Departamento de Enfermagem, Universidade Federal de Santa Catarina; 1997.

NUNES, A. M. P. Concepções Sobre o Processo Saúde-Doença na Enfermagem Ciência e Arte. Texto Contexto Enferm, Florianópolis (SC) I996 jan/jun;5(I):34-45.

SANTIN, S. Cuidando e/ou Confortando: Um paradigma para a Enfermagem. Texto Contexto Enfermagem. Florianópolis (SC) 1998 jan/mar;7(2):III-32

SANTIN, S. Educação Física: ética, estética, saúde. Porto Alegre (RS): Est;1995.

VASCONI, R. La Salud como Problema Existencial. In: I Seminário Internacional de Filosofia e Saúde; 1994 nov. I6-19; Florianópolis (SC), Brasil. Florianópolis (SC): UFSC;1994.

WALDOW, V. R. Cuidado Humano: Resgate Necessário. Porto Alegre (RS):Sagra Luzzatto;1998. 